\title{
A Construção de Recursos Digitais de Matemática: uma experiência de autoria com o Scratch
}

\author{
Darlene Alves Leitão ${ }^{1}$, Juscileide Braga de Castro ${ }^{2}$ \\ ${ }^{1}$ Graduanda em Pedagogia - Faculdade de Educação - Universidade Federal do Ceará \\ (UFC), Fortaleza -CE -Brasil \\ ${ }^{2}$ Professora na Faculdade de Educação - Departamento de Teoria e Prática- \\ Universidade Federal do Ceará (UFC) \\ darlenealvesleitao@gmail.com, juscileide@virtual.ufc.br
}

\begin{abstract}
The insertion of the TDIC in pedagogical practice requires the teacher to reanalyze the teaching processes, considering certain assumptions and theories. This work aims to share the experiences of building digital resources of mathematics from workshop with Scratch. Students of Pedagogy and Mathematics participated in the workshop; teachers of Basic Education and postgraduate students, totaling 14 participants. The workshop provided the instrumentation of Scratch and the possibility of expanding its use beyond the classroom, being used as a tool for the production of digital resources and the construction and conceptual reflection, theoretical and methodological of mathematics.
\end{abstract}

Resumo. A inserção das TDIC na prática pedagógica requisita do professor uma reanálise dos processos de ensino, considerando certos pressupostos e teorias. Este trabalho tem como objetivo compartilhar as experiências de construção de recursos digitais de matemática a partir de oficina com Scratch. Participaram da oficina estudantes da Pedagogia e de Matemática; professores da Educação Básica e alunos da Pós Graduação, totalizando 14 participantes. A oficina proporcionou a instrumentação do Scratch e a possibilidade de ampliar seu uso para além da sala de aula, sendo utilizada como ferramenta para a produção de recursos digitais e a construção e reflexão conceitual, teórica e metodológica da matemática.

\section{Introdução}

As Tecnologias Digitais de Informação e Comunicação (TDIC) estão cada vez mais presentes na vida das pessoas, principalmente a partir da internet. A web tem mudado e influenciado as áreas: econômica, política, social e educacional, já que o acesso à informação tem ficado cada vez mais fácil e rápido, pois pode ser conseguido, instantaneamente, de qualquer parte do mundo.

De acordo com Lévy (1993) a interface digital alarga o campo do visível, evidenciando a emergente evolução que tem diversificado, facilitado e transmitido informações rapidamente. Assim, as pessoas passam, não apenas a ter mais acesso a informação, mas a interagirem como agente comunicador e produtor de informação e de conhecimento. 
Diante disso, a escola precisa se adaptar e integrar as tecnologias digitais, às novas formas de ensinar e de aprender, ao planejamento e ao currículo escolar [Castro e Castro-Filho 2012]. Para isso, os professores precisam experienciar atividades que possibilitem entender as potencialidades e limitações das TDIC em sala de aula.

A inserção das TDIC na prática pedagógica requisita do professor uma reanálise dos processos de ensino, considerando certos pressupostos e teorias, algo que deve ser realizado desde a formação inicial e em formações continuadas. Esta abordagem vai depender da aproximação do docente com a cultura digital, pois disso depende o desenvolvimento da capacidade de adaptação em diferentes realidades e frente a problemas desconhecidos. Dentre as abordagens com o uso de tecnologias digitais, destacam-se a instrucionista e a construcionista [Papert 2008].

A abordagem instrucionista prevê o uso do computador ou outro dispositivo tecnológico, a partir da informatização dos métodos de ensino tradicionais, ou seja, como uso otimizado da máquina de ensinar [Papert 2008]. Esta interpelação privilegia o treino, a repetição e a memorização de conceitos e fórmulas. Exemplos desta abordagem podem ser verificados em tutoriais, recursos de exercício-e-prática e alguns jogos. Essas características podem ser interessantes para ajudar o professor a administrar o processo de ensino, pois auxilia em correção de provas e de exercícios.

$\mathrm{Na}$ abordagem construcionista o estudante constrói seu conhecimento por intermédio do computador, ao aprender fazendo, ou seja, o computador é usado como máquina a ser ensinada. Neste caso, segundo Papert (2008), o aprendizado acontece quando o aluno constrói um objeto de seu interesse, como um jogo, um vídeo, um desenho, por exemplo. Explorar esta abordagem significa proporcionar a docentes e discentes experiências de autodescoberta em favor do desenvolvimento do raciocínio lógico e da emancipação da criatividade.

Pesquisas têm sido desenvolvidas no intuito de explorar a produção de conhecimento pelos estudantes da Educação básica [Castro e Castro-Filho 2012; Castro 2016] ou no âmbito da formação inicial [Castro et al 2017], com o uso de tecnologias digitais. Estas pesquisas têm em comum a abordagem construcionista, de aprender fazendo, apresentando contribuições para a compreensão conceitual, teórica e metodológica da matemática.

Diante do exposto, este trabalho tem como objetivo compartilhar as experiências do processo de construção de recursos digitais por professores e estudantes da área da educação a partir da oficina com Scratch. Pretende-se apresentar discussões sobre o uso pedagógico do Scratch, além de contribuições dos recursos desenvolvidos.

Nas sessões seguintes, apresentar-se-á e discutir-se-á o Scratch e o seu uso pedagógico. Em seguida, serão detalhados os procedimentos metodológicos, seguido dos resultados e discussões do estudo. Ao final, as considerações finais serão dispostas.

\section{O Scratch e sua utilização no ensino de matemática}

O Scratch ${ }^{1}$ é um ambiente de programação visual, desenvolvido para crianças, que possibilita um primeiro contatos sem um grande estranhamento e receio em relação a

\footnotetext{
${ }^{1}$ Pode ser usado online pelo link: https://scratch.mit.edu/ ou off-line, após download e instalação.
} 
VII Congresso Brasileiro de Informática na Educação (CBIE 2018)

Anais dos Workshops do VII Congresso Brasileiro de Informática na Educação (WCBIE 2018)

programação, permitindo uma ampla criação de projetos, incluindo: animações interativas, histórias animadas, notícias online, relatórios de livros, cartões, vídeos de música, tutoriais, simulações, dentre outros[Maloney et al 2013].

Sápiras (2015) afirma que para a utilização do Scratch, o usuário necessita expressar seus pensamentos na forma de comandos, em que toda ação de qualquer objeto deve ser programada e detalhada. Os comandos são visualizados por meio de blocos que são arrastados para a área de roteiro assim conectados, formando a programação do ambiente.

O processo de criação no Scratch segue uma linha de raciocínio lógico em que a partir do momento em que o usuário inicia o desenvolvimento de algum projeto ele pode associar a sua construção a uma sequência lógica de ações. O Scratch é composto por três seções principais (figura 01): [1] o palco, onde são visualizadas as construções finais; [2] a área de comando, onde ficam dispostos os blocos de cada categoria; e [3] o espaço do roteiro, onde são organizados os comandos da programação.

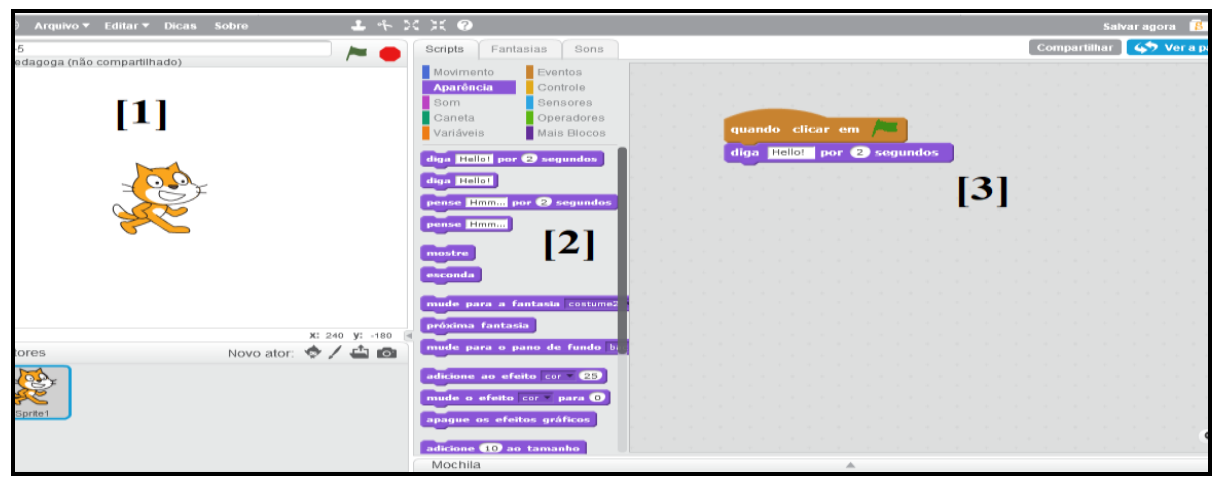

Figura 01: Tela do Scratch

Para Papert (1980) um dos maiores desafios da educação é formar sujeitos reflexivos e construtores de seus próprios projetos. Neste sentido, a aprendizagem requer construir, reconstruir, constatar, para poder intervir e mudar [Bressan e Amaral 2015]. Considerando esta perspectiva, Bressan e Amaral (2015) realizaram oficinas com crianças e adolescentes de uma escola municipal de Araucária, com o objetivo de verificar se a utilização do Scratch pode contribuir para o desenvolvimento do pensamento criativo por meio da aprendizagem baseada em problemas.

Durante a realização da oficina o Scratch mostrou-se potencializador do desenvolvimento de capacidades avaliativas, já que os sujeitos puderam verificar os blocos de comandos usados para resolver os problemas existentes em seus próprios projetos, refletindo sobre eles, o que permitiu a reformulação de resoluções ao detectarem os erros, facilitando a estruturação e a organização do pensamento.

Também foi detectado, nas oficinas realizadas por Bressan e Amaral (2015), a resolução de conflitos cognitivos e o desenvolvimento do pensamento criativo evidenciado na capacidade de solução de problemas, estimulando a (re)formulação, a reflexão, a (re)organização de estratégias para atingir o objetivo proposto pelo próprio estudante em seu projeto. Embora os resultados apresentados não sejam estatisticamente significativos, a utilização do Scratch contribuiu para a construção de conceitos 
VII Congresso Brasileiro de Informática na Educação (CBIE 2018)

Anais dos Workshops do VII Congresso Brasileiro de Informática na Educação (WCBIE 2018)

computacionais e do raciocínio lógico exigido na resolução de alguns problemas matemáticos.

Castro et al (2017) desenvolveram um projeto de produção colaborativa de mídias digitais, junto a estudantes de Licenciatura em Pedagogia, no âmbito da formação inicial, como parte da disciplina de Ensino de Matemática. Os discentes utilizaram princípios do Design Thinking ${ }^{2}$ e ferramentas digitais como o Scratch e o Animaker para produzir 5 mídias que abordam conteúdos como: álgebra, padrões, medidas antropométricas, gráficos e situação de multiplicação. Os resultados indicam que a abordagem construcionista adotada no projeto, de aprender fazendo, contribuiu para a compreensão conceitual, teórica e metodológica dos conteúdos trabalhados ao longo da disciplina.

Ainda que o trabalho de Bressan e Amaral (2015) seja voltado aos discentes e o projeto desenvolvido por Castro et al (2017) tenho como foco os docentes, ou seja, a formação inicial, os dois trabalhos apresentam evidências do potencial de aprendizagem do Scratch e da abordagem construcionista. Na sequência, os procedimentos metodológicos serão dispostos.

\section{Procedimentos Metodológicos da investigação}

Esta pesquisa é caracterizada como qualitativa, pois enfatiza as ações e as experiências da oficina: "Desenvolvendo Recursos Digitais para o Ensino de Matemática com o Scratch". Com o intuito de atender ao objetivo de compartilhar as experiências de construção de recursos digitais de matemática a partir de oficina com Scratch foi realizada uma pesquisa descritiva e explicativa. Pretende-se apresentar discussões sobre o uso pedagógico do Scratch, além de contribuições dos recursos desenvolvidos.

A oficina aconteceu em dois dias, totalizando uma carga horária de 10h/ aulas, no laboratório de Informática Educativa da Faculdade de Educação da Universidade Federal do Ceará (UFC). O público era composto por estudantes das licenciaturas em Pedagogia e Matemática de diferentes universidades (UFC, $\mathrm{UECE}^{3}$ ); professores da Educação Básica e alunos da Pós Graduação - Stricto Sensu em Educação, totalizando 14 participantes. Cerca de 9 participantes não conhecia o Scratch e dos que conheciam, apenas 2 já tinha programado com ele.

Todos os participantes relataram expectativas positivas em relação a oficina. Dentre as expectativas, destaca-se: discussão do uso educacional do Scratch, aprendizagem do uso instrumental e produção de recursos para o ensino de matemática. A oficina teve sua proposta voltada para a construção de recursos digitais, por meio do Scratch, para o ensino de Matemática, tendo como objetivo proporcionar aos participantes experiências com a construção de recursos, enfatizando a importância do processo de construção. A oficina foi dividida em três momentos.

O primeiro momento focou na aprendizagem do uso instrumental da Linguagem de programação. Sendo apresentadas, neste momento, as características do Scratch

\footnotetext{
${ }^{2}$ Uma abordagem que contempla métodos e processos para resolução de problemas com teste das soluções.

${ }^{3}$ Universidade Estadual do Ceará
} 
VII Congresso Brasileiro de Informática na Educação (CBIE 2018)

Anais dos Workshops do VII Congresso Brasileiro de Informática na Educação (WCBIE 2018)

como: estrutura, palco, blocos de comando, área de roteiro, inserção de personagens. Para isso, foram realizadas pequenas atividades que envolvessem relações entre os blocos de comando. No segundo momento da oficina, os participantes tiveram que propor o desenvolvimento de um recurso digital de matemática a partir do Scratch. Para isso, precisaram definir um conteúdo e a forma que este recurso digital seria abordado.

Por fim, no terceiro momento, foram apresentados os recursos digitais desenvolvidos pelos participantes, como uma forma de proporcionar discussões acerca das produções e do uso pedagógico do Scratch e das tecnologias digitais. Os dados analisados foram coletados por meio de observações realizadas durante a oficina (diários de campo); gravações de áudios (entrevistas não estruturadas), e recursos digitais produzidos.

Os critérios para a eleição dos instrumentos de coletas de dados foram determinados de acordo com o objetivo a ser alcançado. Desta forma, elegeu-se como técnicas de coletas de dados a observação e a análise de conteúdo, uma técnica que permite a descrição sistemática, objetiva e qualitativa do conteúdo da comunicação [Lakatos e Marconi 2001]. Os resultados serão apresentados a seguir.

\section{Discussão dos resultados}

A Base Nacional Comum Curricular (BNCC) pontua como uma das suas competências gerais a compreensão, o uso e a criação de tecnologias digitais de informação e de comunicação "de forma crítica, significativa, reflexiva e ética nas diversas práticas sociais (incluindo as escolares)"'[Brasil 2017, p. sn]. Partindo desta competência é interessante perceber a importância da realização de atividades que proporcione o contato do professor com a utilização de tecnologias voltadas para a prática educativa.

Deste modo, a oficina oportunizou entre os participantes, a construção de recursos em um ambiente coletivo, com trocas de ideias e sugestões entre os pares e grupo. Além de possibilitar o contato inicial com Scratch, visto que mais de $85 \%$ do público participante afirmaram não terem tido contato com essa linguagem de programação na construção de projetos digitais, anteriormente. Assim, a oficina representava um desafio como também uma oportunidade de conhecer o Scratch e criar recursos digitais para o ensino de Matemática.

Durante o primeiro dia de oficina os participantes tiveram acesso a diversos exemplos de recursos desenvolvidos por alunos da disciplina de Ensino de Matemática do Curso de Pedagogia [Castro et al 2017] e exemplos de animações e jogos que estão disponíveis do site oficial do Scratch. Após explicações acerca da estrutura e do funcionamento do ambiente de programação visual, os participantes foram desafiados a desenvolverem os seus próprios recursos digitais (RED).

A proposta foi desenvolver um recurso educacional voltado para um público alvo e conteúdo específico. Os materiais desenvolvidos foram apresentados durante o segundo dia da oficina, no qual os participantes tiveram a oportunidade de descrever o seu processo de criação, os seus desafios e pontuar os objetivos educacionais do seu recurso e as possibilidades de uso pedagógico. Os participantes relataram que durante o processo de construção, ao utilizar o Scratch, a cada nova tentativa, aumentava-se a habilidade com o uso da linguagem de programação. 
VII Congresso Brasileiro de Informática na Educação (CBIE 2018)

Anais dos Workshops do VII Congresso Brasileiro de Informática na Educação (WCBIE 2018)

No total, foram produzidos 9 recursos digitais para o ensino de matemática, dentre os quais houve o acesso a 7 recursos, os outros dois não foram compartilhados pelos participantes. Serão discutidos, neste artigo, o processo de construção desses recursos e a análise de dois deles. Todos os recursos compartilhados estão disponíveis no site oficial do Scratch, conforme quadro 1.

Quadro 1 - Lista dos recursos desenvolvidos.

\begin{tabular}{|l|l|l|}
\hline \multicolumn{2}{|c|}{ Nomenclatura dos REDs } & \multicolumn{1}{c|}{ Links de acesso } \\
\hline 1 & Operações matemáticas & $\underline{\text { https://scratch.mit.edu/projects/190318257/ }}$ \\
\hline 2 & Spaece & $\underline{\text { https://scratch.mit.edu/projects/188850354/ }}$ \\
\hline 3 & Jogo da multiplicação & $\underline{\text { https://scratch.mit.edu/projects/188684663/ }}$ \\
\hline 4 & Pokémon e as operações & $\underline{\text { https://scratch.mit.edu/projects/190457492/ }}$ \\
\hline 5 & Uma aventura com Naruto: aprendendo com Rãmen & $\underline{\text { https://scratch.mit.edu/projects/190023355/ }}$ \\
\hline 6 & Tentativa 1 & $\underline{\text { https://scratch.mit.edu/projects/190323543/ }}$ \\
\hline 7 & Movimento e velocidade & $\underline{\text { https://scratch.mit.edu/projects/190385679/ }}$ \\
\hline
\end{tabular}

No decorrer da construção dos RED os participantes tiveram que definir como os conceitos matemáticos seriam abordados em cada recurso, o que propiciou não apenas a instrumentalização do Scratch, mas uma maior reflexão teórica e metodológica da matemática e do uso da tecnologia.

Ainda que a maior parte destes RED tenha sido pensada com uma abordagem instrucionista, as discussões desencadeadas a partir das apresentações de cada proposta individual ou em dupla ao grupo de participantes da oficina provocaram mudanças metodológicas a cada proposta de recurso apresentada no $2^{\circ}$ dia da oficina. Este fato foi identificado na proposta do RED 3, construído por um estudante do $4^{\circ}$ semestre do Curso de Licenciatura em Pedagogia.

O RED 3 apresenta a proposta de realizar o produto de dois números informado pelo usuário, funcionando de forma semelhante a uma calculadora. Embora o RED funcione sem nenhum problema, mostrando que o estudante conseguiu programar a proposta adequadamente, a interação proporcionada ao usuário é pequena (Figura 2). Além disso, não requisita nenhum reflexão, uma vez que a resposta é fornecida ao final.

No terceiro momento, ao final da oficina, o estudante demonstrou o recurso digital ao grupo que fez diversos questionamentos quanto às as contribuições do recurso para o processo de aprendizagem da criança: como este RED pode ajudar na compreensão da operação de multiplicação? Como pode ser usado em uma sala de aula?

Diante dos questionamentos e reflexões dos colegas, o estudante desenvolveu outro RED, em que trabalha as quatro operações (adição, subtração, multiplicação e divisão) por meio de situações problemas (Figura 3). Além disso, segundo o estudante, 
VII Congresso Brasileiro de Informática na Educação (CBIE 2018)

Anais dos Workshops do VII Congresso Brasileiro de Informática na Educação (WCBIE 2018)

utilizou personagens comuns no universo infantil como tema, pois supõe que possa despertar o interesse das crianças em jogar o recurso (RED 4).

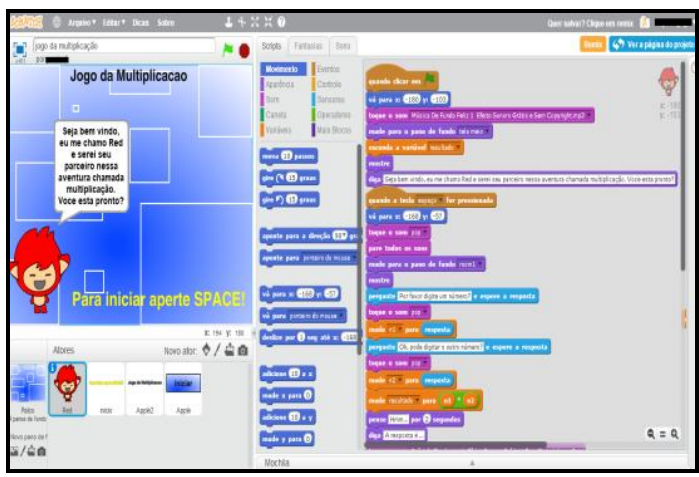

Figura 2: RED 3 - Jogo da Multiplicação

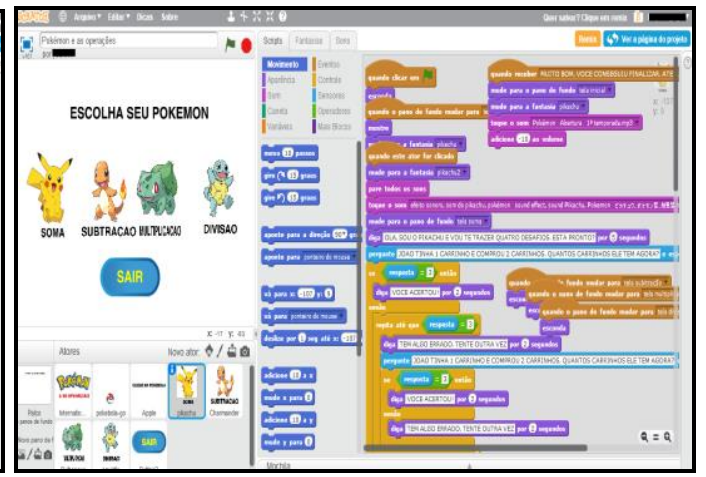

Figura 3: RED 4 - Pokémon e as operações

O RED 4 - Pokémon e as operações (figura 3) apresenta uma linguagem de programação mais complexa se comparada ao RED 3 (figura 2). A estrutura do RED 4, apresenta uma maior variedade de elementos como: personagens, cenários e botões que permitem iniciar ou finalizar o jogo, proporcionando desta forma uma maior interação do usuário diante do recurso.

Ainda que o estudante tenha construído os recursos individualmente, as discussões e troca de experiências entre os participantes propiciou a construção do conhecimento. Percebe-se uma evolução no conhecimento da Linguagem de Programação do Scratch, assim como na compreensão de conceitos e metodologias necessárias ao Ensino de Matemática.

Outra situação observada durante a construção dos RED de Matemática foi o remix. O RED 1 foi criado a partir do RED Operações matemáticas ${ }^{4}$, disponível no Scratch. A modificação contemplou mudanças no background, como personagens e palco, além de mudanças metodológicas e conceituais. O RED de origem contemplava a realização de operações matemáticas (adição, subtração, multiplicação e divisão), sendo que as operações eram resolvidas pelo próprio recurso, a partir de dois números fornecidos. O RED remixado propõe que o usuário resolve uma situação problema com a ideia de juntar, uma atividade que pode ser considerada mais complexa do que a anterior [Vergnaud 1990]. A remixagem possibilitou a compreensão da lógica da linguagem de programação, facilitando a construção do novo RED, possibilitando a reflexão sobre conceitos e metodologias para o ensino de Matemática.

A proposta de incorporar uma narrativa como contexto dos objetivos foi percebido de forma mais evidente no RED 3. Este RED foi desenvolvido por duas estudantes da Licenciatura em Matemática e traz como proposta trabalhar a contagem partindo de recursos visuais. As estudantes criam uma narrativa considerando o contexto do anime Naruto e procuram envolver o jogador durante as atividades, tendo como narradora principal a personagem Sakura que indica para o usuário tudo que precisa ser feito no jogo. A proposta considera o público alvo uma vez que utiliza representações

\footnotetext{
${ }^{4}$ Disponível em: https://scratch.mit.edu/projects/187903968/
} 
VII Congresso Brasileiro de Informática na Educação (CBIE 2018)

Anais dos Workshops do VII Congresso Brasileiro de Informática na Educação (WCBIE 2018)

simbólicas (Rãmen) para relacionar a ideia de quantidade (número) com o numeral (a ser indicado pelo usuário).

É importante considerar que construir um contexto para a aprendizagem pode fornecer um bom motivo para os estudantes empenharem suas energias em aprender.

Todas as apresentações dos RED produzidos na oficina foram seguidas de discussões sobre os recursos e suas possibilidades de uso. Os participantes contribuíram com ideias para o aperfeiçoamento dos recursos que foram apresentados e sugestões de concepções pedagógicas. Essas reflexões e trocas entre os participantes foram considerados pelo próprio grupo como os principais pontos positivos da oficina realizada. Uma das participantes afirmou na avaliação final da oficina que:

Pela ausência de disciplinas mais voltadas para o uso de recursos didáticos
digitais durante a graduação, a participação na oficina apresenta à formação
docente um recurso com infinitas possibilidades de desenvolver atividades
pedagógicas na escola, tendo o professor como produtor de atividades e não
apenas como reprodutor. Ele pode realizar um processo de criação a partir da
necessidade de seu público ( Fala de uma das participantes da oficina)

Ainda que a oficina tenha sido realizada com uma carga horária muito pequena, pode ser percebido por meio das reflexões dos participantes as contribuições que a oficina pode proporcionar em sua formação enquanto docente. Contribuições estas que podem vir a ser vivenciadas na prática pedagógica destes professores. No qual podem vir a utilizar o Scratch como uma ferramenta em sala de aula, que possibilita a produção de seus próprios recursos, considerando sua intencionalidade pedagógica. Outro participante afirmou que:

Através da utilização da ferramenta Scratch e das discussões acercas desta com outros profissionais docentes, pude adquirir experiências e ampliar ideias para a aplicação dessa ferramenta de autoria em sala de aula, ampliando assim minha visão e formação docente. (Fala de um dos participantes da oficina)

Esse processo de compartilhar suas construções e dividir ideias e sugestões durante esse terceiro momento da oficina, proporcionou momentos de aprendizagens, com trocas de experiências e sugestões entre os participantes. Algumas das sugestões de uso dos RED em sala de aula foram: utilização como um espaço avaliativo ou como ferramenta facilitadora do processo de aprendizagem. Também foi citado o uso do próprio Scratch com osaluno na construção de projetos usando a linguagem de programação.

\section{Considerações finais}

Este artigo teve como objetivo compartilhar as experiências de construção de recursos digitais de matemática a partir de oficina com Scratch. Foram apresentadas discussões sobre o uso pedagógico do Scratch, além de contribuições dos recursos digitais desenvolvidos.

Trabalhar com recursos digitais para muitos professores ainda é um grande desafio, construí-los, então, pode ser visto por muitos como algo distante da sua realidade. Papert já apontava em sua obra "Logo: computadores e educação" que a cultura já estava marcada por uma tecnologia onipotente [Papert 1980]. Entretanto, 
atividades de formação voltadas para o uso de tecnologias na educação ainda são escassas no meio acadêmico se comparada a realidade tecnológica vivenciada nos dias atuais.

O que mais prevalece nas escolas é uma concepção de ensino instrucionista em que os docentes insistem em repassar ao aluno aula por aula [Demo 2015]. Esta oficina pode ser considerada um ensaio para uma mudança de paradigma dos participantes, uma vez que foi exercitado a autoria e a autonomia. A passagem de um sistema de ensino instrucionista para um de aprendizagem autoral não é algo simples, pois o desafio de produzir conhecimento próprio, utilizando a instrumentalização metodológica disponível, se contrapõe ao desafio de formar melhor por meio de exercícios de autoria [Demo 2015].

Durante a oficina os participantes tiveram momentos de construção de recursos digitais e troca de experiências entre o grupo. Esses momentos permitiram que os participantes se percebessem atuantes nesse processo de desenvolvimento do RED, e detentores desse conhecimento tecnológico. Cada participante pôde apresentar a sua criação e receber críticas e sugestões sobre o seu projeto, a fim de aperfeiçoá-lo, caso quisesse. As sugestões abordavam questões relacionadas ao uso pedagógico do recurso que envolvia as contribuições pedagógicas dos materiais desenvolvidos. E também foram citados nas sugestões questões envolvendo a linguagem de programação.

A programação com o Scratch incialmente, para a grande maioria, era algo distante da realidade. Entretanto o processo de construção, de desenvolver o seu próprio recurso, possibilitou o desenvolvimento de habilidades em relação ao uso do Scratch. E pode ser constatado no ultimo dia que é possível criar algo a partir das tentativas. E os participantes relataram as suas experiências, dificuldades e aprendizados por meio do criar.

Embora o uso de tecnologias seja algo presente no cotidiano de muitas pessoas e também das crianças, o uso educacional, ou seja, pedagógico, ainda é restrito a poucos ambientes. Infelizmente o acesso às tecnologias, muitas vezes, fica restrito a situações como: jogos, mensagens, conversas, e/ou o uso do celular. Considerando o perfil do jovem da atualidade, dificilmente estes estarão confortáveis em apenas navegar na internet. Vale ressaltar que o acesso e essa familiaridade com as tecnologias não os tornam fluentes em relação ao processo de criação de tecnologias [Resnick 2012].

Assim, a oficina proporcionou a instrumentação do Scratch e a possibilidade de ampliar seu uso para além da sala de aula, podendo ser utilizado como ferramenta para a produção de recursos digitais, trazendo mais autonomia e empoderamento docente, e a construção e reflexão conceitual, teórica e metodológica.

\section{Referências}

Brasil, Ministério da Educação (2017). Base Nacional Comum Curricular. Disponível em $<$ http://basenacionalcomum.mec.gov.br/>Acesso em: 31 Mar. 2018.

Bressan, M. L. Q.; Amaral, M. A. (2015) Avaliando a Contribuição do Scratch para a aprendizagem pela solução de problemas e o desenvolvimento do Pensamento Criativo. Revista Intersaberes, vol.10, n.21, p. 509-526, set.- dez. 2015. Disponível 
VII Congresso Brasileiro de Informática na Educação (CBIE 2018)

Anais dos Workshops do VII Congresso Brasileiro de Informática na Educação (WCBIE 2018)

em: $\quad<$ https://uninter.com/intersaberes/index.php/revista/article/view/866/502>. Acesso em: 14 Abr. 2018

Castro, J. B.; Castro-Filho, J. A. (2012) Projeto Um Mundo de Informações: Integração de Tecnologias Digitais ao Currículo Escolar. In: Congresso Brasileiro de Informática na Educação, 1, 2012, Rio de Janeiro. Anais... Rio de Janeiro: SBC. Disponível em: <http://br-ie.org/pub/index.php/wcbie/article/view/1902/1665>. Acesso em: 14 Abr. 2018.

Castro, J. B.; Soares, I. O; Vianna, E. P. N.; Sousa, J. S.(2017) Lógica Criativa: a construção de mídias digitais para o ensino de matemática. In: VI Congresso Brasileiro de Informática na Educação (CBIE 2017). Anais dos Workshops do VI Congresso Brasileiro de Informática na Educação (WCBIE 2017). Disponível em: $<$ http://www.br-ie.org/pub/index.php/wcbie/article/view/7431/5227>. Acesso em: 14 Abr. 2018.

Demo, Pedro. Aprender como autor. São Paulo: Atlas, 2015.

Lakatos, E. M.; Marconi,, M. A. Fundamentos de metodologia científica. 4 ed. rev. e ampl. São Paulo: Atlas, 2001

Lévy, Pierre. (1993) As tecnologias da inteligência. O futuro do pensamento na era da informática. Tradução Carlos Irineu da Costa. Rio de Janeiro: Editora 34

Maloney, John; Mitchel, Resnick; Natalie, Rusk; Brian, Silverman; Evelyn, Eastmond (2013). The Scratch Programming Language and Environment. $A C M$. v. 10, n. 5, pp 313-338.

Disponível

em: $<\underline{\text { http://web.media.mit.edu/ jmaloney/papers/ScratchLangAndEnvironment.pdf }}>$. Acesso em: 15 Abr. 2018.

Papert, Seymour. Logo: Computadores e Educação. $3^{\mathrm{a}}$ ed. São Paulo: Editora brasiliense S.A. 1980

Papert, Seymour. A Máquina das crianças: repensando a escola na era da informática. Porto Alegre: Artes Médicas, 2008

Resnick, Mitch. Let's teach kids to code. TED: Ideas Worth Spreading. Disponível em $<$ https://www.ted.com/talks/mitch_resnick_let_s teach_kids_to code $>$ Acesso em: 11 Abr. 2018

Sápiras, Fernanda Schuck. Vecchia, Rodrigo Dalla. Maltempi, Marcus Vinicius. Utilização do Scratch em sala de aula. Educ. Matem. Pesq., São Paulo, v.17, n.5, pp. 973 - $\quad 988, \quad 2015 . \quad$ Disponível em $<$ https://revistas.pucsp.br/index.php/emp/article/view/25152> Acesso em: 15. abr 2018

Vergnaud, G. La théorie des champs conceptuels. Recherches en Didactique des Mathématiques, Grenoble, v. 10, n. 23, p. 133-170, 1990. 